\title{
Randomised controlled trial of allopurinol prophylaxis in very preterm infants
}

Regional Neonatal Intensive Care Unit, Department of Child Health, Liverpool Maternity Hospital, Oxford Street, Liverpool L7 7BN G A B Russell R W I Cooke

Correspondence to: Dr Glynn Russell, Department of Child Health, St Michael's Hospital, Southwell Street, Bristol BS2 8EG.

Accepted 6 April 1995

\author{
G A B Russell, R W I Cooke
}

\begin{abstract}
Allopurinol, an inhibitor of xanthine oxidase (an enzyme capable of generating superoxide radicals following hypoxiaischaemia), was investigated in preterm infants to determine its ability to prevent the complications of neonatal intensive care which may be associated with oxidative injury. Four hundred infants of between 24 and 32 weeks' gestation were randomly allocated to receive enteral allopurinol $(20 \mathrm{mg} / \mathrm{ml})$ or an equivalent dose of placebo for seven daily doses. At admission, plasma hypoxanthine concentrations were significantly higher in infants who subsequently developed periventricular leucomalacia (PVL), bronchopulmonary dysplasia (BPD), or retinopathy of prematurity (ROP), but there was no difference in the primary endpoint (PVL) between the treated and control groups.
\end{abstract}

The failure of allopurinol prophylaxis in this group of infants is probably related to the complex nature of the pathological processes and to the timing of treatment. If oxidant injury is an important mechanism of cellular injury in these preterm infants, an alternative biochemical modulator would be required, or a combination of agents might be effective.

(Arch Dis Child 1995; 73: F27-F31)

Keywords: allopurinol, oxygen free radicals, periventricular leucomalacia, hypoxic ischaemia.

A wide range of complications of neonatal intensive care, such as bronchopulmonary dysplasia (BPD), periventricular haemorrhage $(\mathrm{PVH})$, periventricular leucomalacia (PVL), retinopathy of prematurity (ROP), and necrotising enterocolitis (NEC) may be mediated by oxidative tissue injury from the generation of excess oxygen derived free radicals. ${ }^{1}$ The use of scavengers of free radicals such as vitamin $E$ and superoxide dismutase, has a limited effect in reducing the severity of $\mathrm{ROP}^{2}$ and $\mathrm{BPD},{ }^{2-4}$ and possibly also PVH. ${ }^{56}$ The rationale for these clinical trials of free radical scavengers derives from studies suggesting that the antioxidant defences of preterm infants are incompletely developed thereby exposing them to oxidant injury. ${ }^{7-9}$

An alternative might be to reduce free radical production. Although free radicals are produced by a wide variety of metabolic processes, excess production in the newborn may result from the ischaemia-reperfusion phenomenon. ${ }^{10}$ During hypoxia-ischaemia, adenosine is utilised and purine metabolites, such as hypoxanthine, accumulate. Superoxide free radicals are produced during the oxidation of hypoxanthine by xanthine oxidase in the presence of oxygen supplied to the tissue during reperfusion. Allopurinol is a synthetic competitive inhibitor of xanthine oxidase and a free radical scavenger. Treatment with allopurinol reduces free radical production following ischaemia and it reduces tissue injury in in vitro and in vivo experiments. ${ }^{11-16}$ Boda et al, in an unblinded controlled trial, demonstrated reduced mortality from respiratory distress syndrome in a group of preterm babies treated with allopurinol for three days compared with a control group, and suggested that allopurinol may have reduced the generation of superoxide radicals. ${ }^{17}$

We hypothesised that in infants at risk of complications of prematurity, raised concentrations of hypoxanthine would be associated with an increased incidence of these disorders, and secondly that prophylaxis with allopurinol would result in a reduction in the overall incidence of these disorders. We have already reported an association between raised hypoxanthine and periventricular leucomalacia. ${ }^{18}$ The primary hypothesis for this study was, therefore, that early allopurinol treatment would reduce the incidence of PVL in preterm babies.

\section{Method}

Periventricular leucomalacia was selected as the target outcome variable for trial size estimation as this lesion is thought to represent ischaemic infarction of the developing brain and is strongly associated with subsequent abnormalities of neurodevelopment. Initial estimates based on a PVL incidence of $25 \%$ (cavitating and non-cavitating lesions) needed to be revised during the trial as it was clear that the overall incidence of PVL was declining in all patients. To show a $50 \%$ reduction in the incidence of PVL (from $15 \%$ to $7.5 \%$ ) in the treatment group, 200 patients were required in each group to detect this difference at the $5 \%$ significance level $(a=0.05)$ with a power of $80 \%(b=0 \cdot 2)$. Less common complications such as NEC (5\%) and severe blinding ROP $(2 \%)$ were therefore unlikely to be resolved by this trial size.

Infants between 24 and 32 weeks' gestation admitted to the regional neonatal intensive care unit were considered for entry to the trial. Babies of the appropriate gestation were eligible if consent for inclusion was obtained from their parents within six hours, if they were inborn, and 18 hours, if they were outborn. 
Ethical approval for the trial was obtained from the hospital ethics committee. Patients were randomly allocated to allopurinol or placebo groups by opening of sequentially numbered envelopes in which treatment had been determined by computer generated random number allocation, in blocks of 10 to ensure balance between groups. The only stratification was based on place of birth (inborn or outborn) as delay in initiating treatment might have influenced the effect of treatment.

Exclusion factors were restricted to major life threatening malformations, hydrops fetalis, and oesophageal atresia (enteral dosing route was to be used).

\section{DRUG FORMULATION AND DOSE}

Allopurinol was formulated by suspending 20 $\mathrm{mg}$ of allopurinol in mucilage in a concentration of $20 \mathrm{mg} / \mathrm{ml}$ and a single dose of $20 \mathrm{mg} / \mathrm{kg}$ was given daily by oesophageal-gastric tube for seven days. The daily dose of $20 \mathrm{mg} / \mathrm{kg}$ was based on the trial by Boda ${ }^{17}$ and was diluted with an equal volume of water for injection to achieve an osmolality of $409 \mathrm{mOsm} / \mathrm{kg}$.

A placebo, identical in appearance, was formulated by suspending maize starch in mucilage in a concentration of $20 \mathrm{mg} / \mathrm{ml}$ which, when diluted with an equivalent volume of water, gave a final osmolality of 475 $\mathrm{mOsm} / \mathrm{kg}$. The placebo was also administered in a single dose of $20 \mathrm{mg} / \mathrm{kg}$ maize starch per day for seven days. An enteral dose was given because ethical approval was withheld for the parenteral formulation in view of its extreme alkalinity $(\mathrm{pH}=10.5)$ and the parenteral formulation of the drug was only available on a named patient basis for restricted indications.

The median time after birth of the first dose was two hours and 40 minutes (interquartile range one hour 18 minutes to five hours) in the inborn patients and nine hours and 10 minutes (interquartile range five hours 55 minutes to 11 hours 44 minutes) in the outborn patients.

The pharmacokinetics of a single oral dose of $20 \mathrm{mg} / \mathrm{kg}$ allopurinol were investigated before the trial in a similar group of preterm infants (Russell et al, findings submitted for publication). The median (interquartile range) time to maximum plasma concentration (Tmax) was 15 hours (12-22), the median (interquartile range) maximum plasma concentration (Cmax) was $61.6 \mu \mathrm{mol} / 1(22 \cdot 1-148 \cdot 7)$, and the median $\mathrm{t}_{1 / 2}$ was $11 \cdot 7$ hours $(8 \cdot 2-16 \cdot 5)$.

\section{ENDPOINTS OF THE INTERVENTION STUDY}

The primary endpoint for the study was PVL, with secondary clinical endpoints of PVH, porencephaly, ROP, BPD, NEC and death. PVH, porencephaly, and PVL were diagnosed by real time cranial ultrasound scans performed after randomisation, on days 3 and 7, and then weekly until discharge or as close as possible to term. PVH severity was graded according to the classification of Cooke, ${ }^{19}$ and porencephaly was diagnosed if parenchymal echodensities contiguous with large PVH became cavities widely communicating with the ventricles. Non-cavitating PVL was diagnosed as being present if parenchymal echodensity was present for more than 48 hours, and cavitating PVL was defined as one or more echolucencies present in the periventricular parenchyma but not communicating with the ventricles. ROP was detected by serial examinations by a consultant ophthalmologist from 32 weeks' postconceptual age or at least four weeks after birth and every two weeks thereafter. The ROP was classified according to the International Classification of Diseases. BPD was regarded as being present if babies were ventilated for RDS and were still oxygen dependent after 28 days, and if they had a compatible chest $x$-ray picture. NEC was defined as clinical evidence of abdominal distension and ileus, systemic illness, and a reduction in platelet count with or without blood passed through the rectum. Abdominal $x$-ray evidence of bowel distension, with or without intramural air or perforation, was also required.

\section{BIOCHEMICAL ANALYSIS}

Plasma samples were drawn from the umbilical cord or baby as soon after admission as possible and then on days 3 and 7. Estimations were made of purines (hypoxanthine and oxypurine), allopurinol and oxypurinol. Purines and allopurinol were measured by high power liquid chromatography (HPLC), as reported before. ${ }^{18}$

Direct identification of free radical generation in preterm babies is technically difficult. Indirect detection by measurement of lipid peroxidation products (thiobarbituric acid reacting substances or TBARS) has been widely used, although this is a non-specific method for detection of free radical activity. TBARS were measured using the fluorometric method of Yagi, ${ }^{20}$ but this method has since been shown to be prone to artefact and HPLC would now be used in preference. ${ }^{21} 22$

\section{STATISTICS}

Predetermined endpoints were analysed between groups on an intention-to-treat basis. Dichotomous variables were analysed using the $\chi^{2}$ test and biochemical assays were analysed using the Mann-Whitney U test.

\section{Results}

A total of 400 babies were enrolled in the trial. Effective randomisation was achieved between the two groups, but because of two changes in code allocation to allow for interim analysis, 205 infants were randomised to the allopurinol group and 195 to placebo (table 1 ).

Although the proportion of babies who died $(34 / 205 v 20 / 195)$ was higher in the allopurinol group, the difference was not significant. No significant differences were shown in the proportion of babies who developed PVH, PVL, porencephaly, NEC, ROP, or BPD (table 2 ). No difference was noted between inborn and outborn babies except that the outborn 
Table 1 Demographic data (medians and interquartile range or \%)

\begin{tabular}{lcc}
\hline & Allopurinol & Placebo \\
\hline Number & 205 & 195 \\
Gestation (weeks) & 29 & 29 \\
(interquartile range) & $27-31$ & $27-31$ \\
Weight (g) & 1240 & 1298 \\
$\quad$ (interquartile range) & $944-1540$ & $970-1550$ \\
Male sex (\%) & 54 & 48 \\
RDS (\%) & $69 \cdot 7$ & $69 \cdot 7$ \\
Steroids (\%) & 48.9 & $49 \cdot 4$ \\
Outborn (\%) & 18.5 & 18.5 \\
\hline
\end{tabular}

patients, as a whole, had a higher incidence of PVH and parenchymal cavitation. Using multiple logistic regression modelling with independent variables of treatment group, weight, gestation, sex, antenatal steroids and surfactant therapy, and the predefined endpoints as dependent variables, no significant differences were detected between groups that did and did not develop specific outcomes.

\section{BIOCHEMICAL ANALYSES}

Stable levels of the major active metabolite oxypurinol were achieved during daily dosing with allopurinol and there was no significant evidence of accumulation. The median oxypurinol concentration (95\% CI) 24 hours after the first dose of allopurinol was 26.4 $\mu \mathrm{mol} / 1 \mathrm{l}(11 \cdot 7-32.0 \mu \mathrm{mol} / \mathrm{l})$. The daily median concentrations thereafter were $39 \cdot 1 \mu \mathrm{mol} / 1$ $(31 \cdot 0-56 \cdot 8), 42 \cdot 2 \mu \mathrm{mol} / 1(34 \cdot 8-51 \cdot 0), 44 \cdot 0$ $\mu \mathrm{mol} / 1(32 \cdot 4-72 \cdot 6), 48 \cdot 2 \mu \mathrm{mol} / 1(40 \cdot 4-56 \cdot 3)$, and $48 \cdot 2 \mu \mathrm{mol} / 1(37 \cdot 9-63 \cdot 3)$. A significant and consistent decline in uric acid was observed within 24 hours of starting allopurinol and the natural decline in uric acid was delayed until towards the end of the first week (figure).

Plasma hypoxanthine concentrations (pretreatment) on admission of all 400 patients were significantly higher in infants developing PVL, ROP, and BPD (table 3). The median (interquartile range) hypoxanthine concentration in the placebo group was $8.0 \mu \mathrm{mol} / \mathrm{l}$

Table 2 Occurrence of primary (PVL) and secondary endpoints in allopurinol treated and control groups

\begin{tabular}{cll}
\hline & $\begin{array}{l}\text { Allopurinol } \\
n(\%)\end{array}$ & $\begin{array}{l}\text { Control } \\
n(\%)\end{array}$ \\
\hline Total & 205 & 195 \\
Died & 34 & 20 \\
$95 \%$ CI & $(16 \cdot 6)$ & $(10 \cdot 2)$ \\
& $(11 \cdot 8-22 \cdot 4)$ & $(6 \cdot 4-15 \cdot 4)$ \\
PVH (all grades): & 114 & 97 \\
$95 \%$ CI & $(55 \cdot 6)$ & $(49 \cdot 7)$ \\
PVL: & $(48 \cdot 5-62 \cdot 5)$ & $(42 \cdot 5-57 \cdot 0)$ \\
$95 \%$ CI & 9 & 5 \\
Porencephaly: & $(4 \cdot 4)$ & $(2 \cdot 6)$ \\
$95 \%$ CI & $(2 \cdot 0-8 \cdot 1)$ & $(\star)$ \\
BPD: & 14 & 10 \\
$95 \%$ CI & $(6 \cdot 8)$ & $(5 \cdot 1)$ \\
ROP (all grades): & $(3 \cdot 8-11 \cdot 2)$ & $(2 \cdot 5-9 \cdot 2)$ \\
$95 \%$ CI & 48 & 48 \\
ROP (treated): & $(23 \cdot 4)$ & $(24 \cdot 6)$ \\
$95 \%$ CI & $46 \cdot 8-29 \cdot 8)$ & $(18 \cdot 7-31 \cdot 3)$ \\
& $(22 \cdot 4)$ & 48 \\
NEC: & $(16 \cdot 9-28 \cdot 8)$ & $(24 \cdot 6)$ \\
$95 \%$ CI & $(2 \cdot 9)$ & $(18 \cdot 7-31 \cdot 3)$ \\
& $(1 \cdot 1-6 \cdot 3)$ & $(5 \cdot 6)$ \\
& 10 & $(2 \cdot 8-9 \cdot 9)$ \\
\hline
\end{tabular}

Complete fundoscopy results available on $59 \%$ of allopurinol group and $61 \%$ of controls only. ${ }^{\star}$ Too few for $95 \%$ CI.
$(5 \cdot 8-14 \cdot 7 \mu \mathrm{mol} / \mathrm{l})$ on day 1 , and significantly lower on day $3(2 \cdot 8 \mu \mathrm{mol} / 1(1 \cdot 9-5 \cdot 2 \mu \mathrm{mol} / \mathrm{l})$; $\mathrm{P}<0.0001)$ and on day $7(2 \cdot 3 \mu \mathrm{mol} / 1(1 \cdot 3-4 \cdot 5$ $\mu \mathrm{mol} / \mathrm{l}) ; \quad \mathrm{P}<0.0001)$. The hypoxanthine concentration in the allopurinol group was $7.6 \mu \mathrm{mol} / 1(5.4-14.9 \mu \mathrm{mol} / \mathrm{l})$ on day 1 and, as expected, rose on day $3(28.0 \mu \mathrm{mol} / 1$ $(13.8-52.4 \mu \mathrm{mol} / \mathrm{l})$ ), because of xanthine oxidase inhibition, and returned to low values by day $7(4 \cdot 15 \mu \mathrm{mol} / 1(2 \cdot 4-8 \cdot 2 \mu \mathrm{mol} / \mathrm{l}))$. There was no correlation between hypoxanthine on days 3 or 7 with morbidity in either group.

The concentration of lipid peroxidation products (TBARS) rose during the seven days of sampling from $2.05 \mu \mathrm{mol} / 1(1 \cdot 4-2 \cdot 7 \mu \mathrm{mol} / \mathrm{l})$ (median (interquartile range)) on day 1 to $3 \cdot 4$ $\mu \mathrm{mol} / / \mathrm{l}(3 \cdot 0-4.4 \mu \mathrm{mol} / \mathrm{l})$ on day 3 , and to $3 \cdot 18$ $\mu \mathrm{mol} / \mathrm{l}(2 \cdot 4-4.4 \mu \mathrm{mol} / \mathrm{l})$ on day 7 . There were no differences in the values between the two treatment groups. Only babies with PVL had a significantly higher TBARS on day 1 (median $3.06 \mu \mathrm{mol} / 1$ and interquartile range 1.78 to 4.44) compared with the group without PVL (median $2.14 \mu \mathrm{mol} / 1$ and interquartile range $1 \cdot 61-2 \cdot 77 \mu \mathrm{mol} / \mathrm{l})(\mathrm{P}<0 \cdot 05)$.

\section{Discussion}

In this trial of prophylactic allopurinol for the prevention of PVL in preterm babies, no protective effect was apparent. An excess of the primary endpoint of PVL and the secondary endpoints of mortality, porencephaly, and NEC in the treated group compared with the control group was not significant. There were no differences in the incidence of BPD and the overall incidence of ROP, but although fewer cases of severe ROP (treated) occurred in the allopurinol treatment group, this difference was also not significant: a much larger trial would be required.

These differences might have been due to chance, such as recruitment of sicker infants to

Table 3 Admission hypoxanthine values and outcome irrespective of treatment (medians and interquartile range)

\begin{tabular}{|c|c|c|c|}
\hline & & $\begin{array}{l}\text { Hypoxanthine ( } \mu \text { moll) } \\
\text { (median and } I Q R)\end{array}$ & $P$ Value \\
\hline Outcome: & $\begin{array}{l}\text { Alive } \\
158 \\
\text { Dead } \\
26\end{array}$ & $\begin{array}{l}7 \cdot 55 \\
5 \cdot 58-14 \cdot 7 \\
9 \cdot 2 \\
5 \cdot 5-17 \cdot 48\end{array}$ & $\begin{array}{l}U=1893 \cdot 0 \\
P=0.5223\end{array}$ \\
\hline PVH: & $\begin{array}{l}\text { None or grade } 1 \\
(n=90) \\
\text { Grade } 2-3 \\
(n=94)\end{array}$ & $\begin{array}{l}7 \cdot 10 \\
(5 \cdot 40-11 \cdot 98) \\
8 \cdot 85 \\
(5 \cdot 60-18 \cdot 1)\end{array}$ & $\begin{array}{l}U=3525 \cdot 0 \\
P=0.0509\end{array}$ \\
\hline PVL: & $\begin{array}{l}\text { None } \\
(n=130) \\
\text { Present } \\
(n=16)\end{array}$ & $\begin{array}{l}7 \cdot 15 \\
(5 \cdot 30-12 \cdot 82) \\
13 \cdot 75 \\
(6 \cdot 15-56 \cdot 48)\end{array}$ & $\begin{array}{l}U=399 \cdot 5 \\
P=0.0427\end{array}$ \\
\hline POR: & $\begin{array}{l}\text { None } \\
130 \\
\text { Present } \\
17\end{array}$ & $\begin{array}{l}7 \cdot 15 \\
5 \cdot 30-12 \cdot 82 \\
12 \cdot 7 \\
6 \cdot 50-17 \cdot 45\end{array}$ & $\begin{array}{l}U=850 \cdot 5 \\
P=0 \cdot 1230\end{array}$ \\
\hline$B P D:$ & $\begin{array}{l}\text { No } \\
123 \\
\text { Present } \\
43\end{array}$ & $\begin{array}{l}7 \cdot 0 \\
5 \cdot 4-12 \cdot 8 \\
11 \cdot 4 \\
7 \cdot 0-18 \cdot 3\end{array}$ & $\begin{array}{l}U=1862 \\
P=0.0039\end{array}$ \\
\hline ROP: & $\begin{array}{l}<\text { Grade } 3 \\
82 \\
>\text { Grade } 3 \\
21\end{array}$ & $\begin{array}{l}6 \cdot 85 \\
5 \cdot 45-11 \cdot 4 \\
12 \cdot 3 \\
8 \cdot 65-18 \cdot 65\end{array}$ & $\begin{array}{l}U=437.5 \\
P=0.005\end{array}$ \\
\hline$N E C:$ & $\begin{array}{l}\text { No } \\
164 \\
\text { Present } \\
10\end{array}$ & $\begin{array}{l}7 \cdot 55 \\
5 \cdot 6-14 \cdot 2 \\
9 \cdot 15 \\
3 \cdot 48-22 \cdot 52\end{array}$ & $\begin{array}{l}\mathrm{U}=775 \cdot 5 \\
\mathrm{P}=0.7735\end{array}$ \\
\hline
\end{tabular}




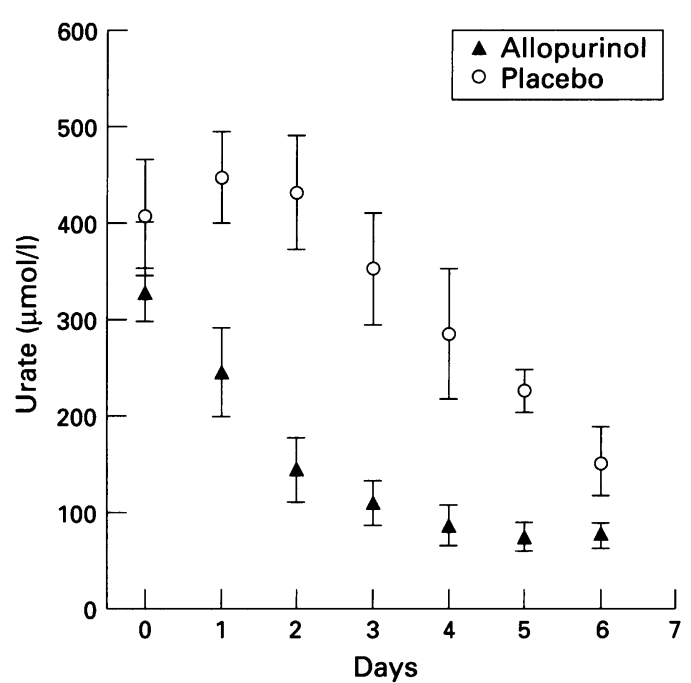

Mean (SE) daily plasma urate concentration in babies receiving daily allopurinol $(\Delta)(n=16)$ or placebo (O) $(n=17)$.

the treatment group. Boys were overrepresented in the treatment group, and are known to have a poorer outcome. Alternatively, allopurinol may accentuate rather than reduce tissue injury or may have toxic effects which could have accounted for the differences in outcome. No unexplained events were noted in the treatment group and there was no excess of known complications of allopurinol, such as renal failure, hepatitis, or mucocutaneous eruptions. The fact that not all endpoints showed differences in the same direction also suggests that allopurinol did not accentuate the injury. Organ specific effects, possibly due to differences in xanthine oxidase activity, are possible; or allopurinol, by reducing plasma uric acid, may have reduced the potential antioxidant activity of plasma. ${ }^{23}$ There is no evidence that enteral starch used in the placebo would confer a cytoprotective effect.

Hypoxanthine concentrations on admission to the trial were significantly higher in patients who developed PVL, BPD, and ROP, suggesting that these babies had experienced a period of hypoxia during the immediate antepartum period. Evidence of lipid peroxidation on day 1 was also significantly greater in the nine babies who developed PVL. A rise in the TBARS by day 3 was seen in most babies regardless of the presence of complications or treatment group. Inhibition of xanthine oxidase was clearly demonstrated by the significant reduction in uric acid and the rise in hypoxanthine in the treated patients. It is assumed that xanthine oxidase at all relevant sites such as cerebral, retinal, hepatic and pulmonary vascular endothelial cells was inhibited. The presence of xanthine oxidase in the organs affected in disorders of prematurity is central to the hypothesis of hypoxic ischaemia and the role of pharmacological inhibition in the prevention of these disorders. The distribution of xanthine oxidase seems to be subject to both tissue ${ }^{24}$ and species ${ }^{25}$ variation and this may account for the conflicting effects of allopurinol treatment in different animal models.

Human xanthine oxidase activity is present throughout gestation, particularly in liver and intestine but activity is low in brain. ${ }^{26}$ The enzyme is found predominantly in endothelial cells including cerebral capillary endothelium. ${ }^{24}$ Circulating xanthine oxidase found in sick patients ${ }^{23}$ could also account for tissue injury even though the resident enzyme activity is low.

Antioxidants for cerebral protection in tissue and animal models have demonstrated the role of free radicals in cerebral injury and have raised the possibility of their use in clinical treatment. Clinical trials in newborn infants have been confined to vitamin $\mathbf{E}$ for the prevention of intraventricular haemorrhage ${ }^{56}$ but allopurinol effects cerebral protection in rats and dogs. The high doses used in animal experiments $(50-200 \mathrm{mg} / \mathrm{kg}$ ) compared with the dose of $20 \mathrm{mg} / \mathrm{kg}$ used in this trial may account for the cerebral protection seen in rats $^{2829}$ and $\operatorname{dogs}^{30}$ but this effect may have been due to more effective xanthine oxidase inhibition and possibly also to its ability to scavenge free radicals, ${ }^{31}$ and to chelate transitional metals such as copper ${ }^{11}$ ions. ${ }^{32}$ All these experiments used pretreatment (before the hypoxic-ischaemic insult) with allopurinol which may be more effective.

The use of superoxide dismutase to reduce oxidant lung injury in preterm infants and prevent bronchopulmonary dysplasia ${ }^{3}$ is encouraging but has not been confirmed in further clinical trials despite animal experiments demonstrating tissue protection.

Allopurinol has not been used before to prevent $\mathrm{BPD}$, but a recent report suggests that allopurinol may modify acute lung injury in premature baboons requiring additional inspired oxygen and mechanical ventilation for respiratory distress. ${ }^{33}$ Allopurinol attenuates porcine pulmonary vascular vasoconstriction which occurs with infusion of xanthine oxidase and hypoxanthine, ${ }^{34}$ and a hypoxanthine infusion plus oxygen causes lung injury in rats. ${ }^{35}$

Although we found an association between raised hypoxanthine activity and BPD, we were unable to demonstrate any difference in the incidence of BPD with allopurinol treatment. This may indicate that the acute lung injury was not primarily mediated by xanthine oxidase, hypoxanthine, and oxygen, or that enteral allopurinol failed to inhibit the enzyme before the injury had occurred.

The pathogenesis of ROP is also complex but is thought to involve oxidant injury to the developing retinal vessels. The oxidant injury may involve exposure to high partial pressure of oxygen, the presence of transitional metals such as iron ${ }^{11}$ ions or hypoxic ischaemia. Despite the apparent protection by allopurinol of cat retinal vessels following hypoxic ischaemia $^{36}$ we have not been able demonstrate a reduction in ROP in babies treated with allopurinol.

Allopurinol has also been effective in modifying injury in animal models of hypoxic ischaemic organ damage to intestine, ${ }^{11}{ }^{12} \mathrm{kid}$ ney, ${ }^{1314}$ and liver. ${ }^{1516}$ Gastrointestinal mucosal xanthine oxidase activity may have a 
role in ischaemic injury such as NEC. The greater number of cases of NEC in the allopurinol group was not unexpectedly high compared with the usual incidence, but because of the enteral route used for dosing and the possible association of hyperosmolar feeds and NEC, the enteral route for administration could be a factor in the pathogenesis of NEC. The osmolality of the placebo, however, was higher than that of allopurinol and the incidence of NEC was much lower, so this explanation seems unlikely.

We have not been able to confirm the results of Boda et al. ${ }^{17}$ Although we used the same dose and route of administration of allopurinol, our patients were significantly smaller and probably of a lower gestation as Boda selected patients between $1000 \mathrm{~g}$ and $2500 \mathrm{~g}$. The trials are therefore not comparable.

The reasons for the failure of allopurinol to prevent the complications of prematurity are therefore unclear but could be due to one or more of the following factors. Firstly, hypoxic ischaemia may not be the primary pathogenic mechanism of tissue injury. Secondly, although xanthine oxidase may be inhibited by the dose used, additional effects of allopurinol may be dose dependent and higher doses may have been effective. Thirdly, the enteral route of administration or the timing of the first dose (possibly after the first hypoxic ischaemic insult) may have delayed xanthine oxidase inhibition and allowed the tissue injury process to become well established. Finally, the duration of treatment may have been too short, particularly for disorders which may involve repeated insults such as ROP and BPD.

Further clinical work with allopurinol might use higher doses or parenteral administration to achieve protection.

We gratefully acknowledge the contributions to this study of the nursing and medical staff of the Regional Neonatal Intensive Care Unit, Liverpool, and Miss Linda Matthew, pharmacist, and Mr Graham Jeffers, biochemistry laboratory officer.

1 Saugstad O. Hypoxanthine as an indicator of hypoxia: its role in health and disease through free radical production. Pediatr Res 1988; 23: 143-50.

2 Sinclair J, Bracken M, eds. Effective care of the newborn infant. Oxford: Oxford University Press, 1992.

3 Rosenfield W, Evans H, Concepcion L, Jhavin R, Schaeffer H, Friedman A. Prevention of bronchopulmonary dysplasia by administration of bovine superoxide dismutase in preterm infants with respiratory distress syndrome. $f$ preterm infants with respir

4 Ehrenkrantz R, Ablow R, Warshaw J. Effect of vitamin E on the development of oxygen-induced lung injury in neonates. Ann NY Acad Sci 1982; 393: 452-66.

5 Sinha S, Davies J, Toner N, Bogle S, Chiswick M. Vitamin $\mathrm{E}$ supplementation reduces frequency of periventricular haemorrhage in very preterm babies. Lancet 1987; i: 466-71.

6 Fish W, Cohen M, Franzek D, Williams J, Lemons J. Effect of intramuscular Vitamin $\mathrm{E}$ on mortality and intracrania hemorrhage in neonates of 1000 grams or less. Pediatrics 1990; 85: 578-84.

7 Autor A, Frank L, Roberts R. Developmental characteristics of pulmonary superoxide dismutase: relationship to the idiopathic respiratory distress syndrome. Pediatr Res 1976; 10: $154-8$.

8 Tanswell A, Freeman B. Pulmonary antioxidant enzyme maturation in the fetal and neonatal rat. 1. Developmental profiles. Pediatr Res 1984; 18: 584-7.
9 Gerdin E, Tyden O, Erikson U. The development of antioxidant enzymatic defense in the perinatal lung. Activities of superoxide dismutase, glutathione peroxidase and catalase. Pediatr Res 1985; 19: 687-91.

$10 \mathrm{McCord}$ JM. Oxygen-derived free radicals in postischemic tissue injury. N Engl $\mathcal{F}$ Med 1985; 312: 159-63.

1 Parks DA, Bulkley GB, Granger DN, Hamilton SR Ischemic injury in the cat small intestine: role of superoxide radicals. Gastroenterology 1982; 82: 9-15.

12 Boros M, Karacsony G, Kaszaki J, Nagy S. Reperfusion mucosal damage after complete intestinal ischemia in the dog: the effects of antioxidant and phospholipase A2 inhibitor therapy. Surgery 1993; 113: 184-91.

13 Bratell S, Haraldsson G, Herlitz H, Jonsson O, Pettersson $\mathrm{S}$, Schersten T, et al. Protective effects of pretreatment $\mathrm{S}$, Schersten $\mathrm{T}$, et al. Protective effects of pretreatment with superoxide dismutase, catalase and oxypurinol on Physiologica Scandinavica 1990; 139: 417-25.

14 Rosati R, Stortoni F, Filingeri V, Svegliati F, Cervelli V, Casciani CU. Allopurinol and superoxide dismutase administration in prevention of rat kidney ischemic injury. Transplant Proc 1988; 20: 928-30.

15 Cho WH, Kim DG, Murase N, Mischinger HJ, Todo S, Starzl TE. Comparison of superoxide dismutase, allopurinol, coenzyme Q10, and glutathione for the prevention of warm ischemic injury. Transplantation 1990; 50: 353-5.

16 Grune T, Siems WG, Schneider W. Accumulation of aldehydic lipid peroxidation products during postanoxic reoxygenation of isolated rat hepatocytes. Free Rad Biol Med 1993; 15: 125-32.

17 Boda D, Nemeth I, Hencz P, Denes K. Effect of allopurinol treatment in premature infants with idiopathic respiratory distress syndrome. Dev Pharmacol Ther 1984; 7: 357-67.

18 Russell GAB, Jeffers G, Cooke RWI. Plasma hypoxanthine: a marker for hypoxic-ischaemic induced periventricula leucomalacia. Arch Dis Child 1992; 67: 388-92.

19 Cooke R. Early and late cranial ultrasonographic appearances and outcome in very low birthweight infants. Arch Dis Child 1987; 62: 931-7.

20 Yagi K. A simple fluorometric assay for lipoperoxide in blood plasma. Biochem Med 1976; 15: 212-6.

21 Gutteridge J, Halliwell B. The measurement and mechanism of lipid peroxidation in biological systems. Trends Biochem Sci 1990; 15: 129-35.

22 Halliwell B, Chirico S. Lipid peroxidation: Its mechanism, measurement and significance. Am 7 Clin Nutr 1993; 57: 715-25S.

23 Tan S, Radi R, Gaudier F, Evans RA, Rivera A, Kirk KA, et al. Physiologic levels of uric acid inhibit xanthine oxidase in human plasma. Pediatr Res 1993; 34: 303-7.

24 Jarasch E-D, Bruder G, Heid HW. Significance of xanthine oxidase in capillary endothelial cells. Acta Physiol Scand 1986; 548 (suppl): 39-46.

25 Al-Khalidi U, Chaglassian T. The species distribution of xanthine oxidase. Biochem f 1965; 97: 318-20.

26 Vettenranta K, Raivio KO. Xanthine oxidase during fetal development. Pediatr Res 1990; 27: 286-8.

27 Betz AL. Identification of hypoxanthine transport and xanthine oxidase activity in brain capillaries. 7 Neurochem 1985; 44: 574-9.

28 Palmer C, Vannucci RC, Towfighi J. Reduction of perinatal hypoxic-ischemic brain damage with allopurinol. Pediatr Res 1990; 27: 332-6.

29 Itoh T, Kawakami M, Yamauchi Y, Shimizu S, Nakamura $M$. Effect of allopurinol on ischemia and reperfusioninduced cerebral injury in spontaneously hypertensive rats. Stroke 1986; 17: 1284-7.

30 Mink RB, Dutka AJ, Hallenbeck JM. Allopurinol pretreatment improves evoked response recovery following global cerebral ischemia in dogs. Stroke 1991; 22: 660-5.

31 Das DK, Engelman RM, Clement R, Otani H, Prasad MR Rao PS. Role of xanthine oxidase inhibitor as free radical scavenger: a novel mechanism of action of allopurinol and oxypurinol in myocardial salvage. Biochem Biophys Res Comm 1987; 148: 314-9.

32 Malkiel S, Har R, Schwalb H, Uretzky G, Borman JB, Chevion $M$. Interaction between allopurinol and copper: possible role in myocardial protection. Free Rad Res Comm possible role in my

33 Jenkinson SG, Roberts RJ, DeLemos RA, Lawrence RA. Allopurinol-induced effects in premature baboons with respiratory distress syndrome. F Appl Physiol 1991; 70: 1160-7.

34 Sanderud J, Norstein J, Saugstad O. Reactive oxygen metabolites produse pulmonary vascoconstriction in young pigs. Pediatr Res 1991; 29: 543-7.

35 Saugstad O, Hallman M, Abraham J, Epstein B, Cochrane C, Gluck L. Hypoxanthine and oxygen induced lung injury: a possible basic mechanism of tissue damage? Pediatr Res 1984; 18: 501-4.

36 Peachey NS, Green DJ, Ripps H. Ocular ischemia and the effects of allopurinol on functional recovery in the retina of the arterially perfused cat eye. Invest Ophthalmol Vis Sci of the arterially perf 